\author{
SELECTED ABSTRACTS FROM THE \\ JOURNAL OF THE EXPERIMENTAL \\ ANALYSIS OF BEHAVIOR, NOVEMBER 1993
}

\title{
CONDITIONAL DISCRIMINATION IN MENTALLY \\ RETARDED SUBJECTS: PROGRAMMING ACQUISITION AND LEARNING SET
}

\author{
Kathryn J. Saunders and Joseph E. SPRadlin
}

\author{
UNIVERSITY OF KANSAS
}

In Experiment 1, 3 subjects with retardation were exposed to two visual-visual arbitrary matchingto-sample problems each day. One conditional discrimination was presented under trial-and-error conditions, and the other was presented under a component training procedure. The latter began by establishing the comparison discrimination and its rapid reversal. The successive discrimination between the sample stimuli was established through differential naming. Then, sample naming was maintained in conditional discrimination sessions in which the same sample was presented in blocks of consecutive trials. Block size was decreased across sessions until sample presentation was randomized as in trial-and-error training (but with naming maintained). Two subjects initially learned only with component training. The performance of the 3rd subject was inconsistent across conditional discriminations. One of the successful subjects ultimately learned rapidly and consistently with trial-anderror procedures. Experiment 2 sought to demonstrate learning set in the other 2 subjects. Elements of the component training procedure were withdrawn over successive conditional discriminations. Ultimately, 1 subject nearly always learned under trial-and-error conditions, and the other learned under trial-and-error conditions combined with differential sample naming.

Key words: conditional discrimination, matching to sample, learning set, button press, mentally retarded subjects

\section{THE EFFECT OF INCREASED RESPONSE REQUIREMENTS ON DISCRIMINATIVE PERFORMANCE OF THE DOMESTIC HEN IN A VISUAL ACUITY TASK}

\author{
Lesley R. DeMello, T. Mary Foster, and William Temple
}

\section{BALLARAT UNIVERSITY COLLEGE, BALLARAT, AUSTRALIA AND UNIVERSITY OF WAIKATO, HAMILTON, NEW ZEALAND}

Six domestic hens were trained in a spatial discrimination task. A controlled reinforcement procedure insured that the ratio of scheduled and obtained reinforcement remained equal. Gray stimuli and gratings ranging in spatial frequency from 1 to 10 cycles per millimeter were presented in seven descending series of probes. The response requirement to the sample key was varied from fixed ratio 1 to fixed ratio 40 in seven experimental conditions. An increase in response requirements from fixed ratio 1 to fixed ratio 5 and fixed ratio 10 resulted in significantly higher accuracy at discriminable grating values. Further increases in response requirements did not consistently improve performance. Generally, response biases increased and occasionally became extreme for probes at finer gratings with increased response requirements.

Key words: discrimination, response requirement, matching to sample, visual acuity, key peck, hens 


\section{SIGNAL-DETECTION PROPERTIES OF VERBAL SELF-REPORTS Thomas S. GritchField

\author{
AUBURN UNIVERSITY
}

The bias $\left(B^{\prime}{ }_{H}\right)$ and discriminability $\left(A^{\prime}\right)$ of college students' self-reports about choices made in a delayed identity matching-to-sample task were studied as a function of characteristics of the response about which they reported. Each matching-to-sample trial consisted of two, three, or four simultaneously presented sample stimuli, a 1-s retention interval, and two, three, or four comparison stimuli. One sample stimulus was always reproduced among the comparisons, and choice of the matching comparison in less than $800 \mathrm{~ms}$ produced points worth chances in a drawing for money. After each choice, subjects pressed either a "yes" or a "no" button to answer a computer-generated query about whether the choice met the point contingency. The number of sample and comparison stimuli was manipulated across experimental conditions. Rates of successful matching-to-sample choices were negatively correlated with the number of matching-to-sample stimuli, regardless of whether samples or comparisons were manipulated. As in previous studies, subjects exhibited a pronounced bias for reporting successful responses. Self-report bias tended to become less pronounced as matching-tosample success became less frequent, an outcome consistent with signal-frequency effects in psychophysical research. The bias was also resistant to change, suggesting influences other than signal frequency that remain to be identified. Self-report discriminability tended to decrease with the number of sample stimuli and increase with the number of comparison stimuli, an effect not attributable to differential effects of the two manipulations on matching-to-sample performance. Overall, bias and discriminability indices revealed effects that were not evident in self-report accuracy scores. The results indicate that analyses based on signal-detection theory can improve the description of correspondence between self-reports and their referents and thus contribute to the identification of environmental sources of control over verbal self-reports.

Key words: self-reports, matching to sample, signal detection, discriminability, bias, signal-frequency effects, button press, button release, college students 